\title{
Siting military base camps through an MCDA framework
}

DOI 10.2478/jms-2021-0014

Received: February 1, 2018; Accepted: July 10, 2021

\begin{abstract}
The process used to determine site suitability for military base camps lacks a formal framework for reducing relative risks to soldier safety and maximise mission effectiveness. Presently, military personnel responsible for determining site suitability of a base camp must assess large amounts of geographic, socioeconomic and logistical data, without a decision analysis framework to aid in the process. By adopting a multicriteria decision analysis (MCDA) framework to determine site suitability of base camps, battlespace commanders can make better, more defensible decisions. This paper surveys US Army officers with recent base camp experience to develop a set of initial criteria and weights relevant to base camp site selection. The developed decision framework is demonstrated using an MCDA methodology in an illustrative example to compare alternative base camp locations within a designated Area of Interest (AoI). Leveraging the site ranking output and/or criteria weights resulting from the methodology provides decision-making support that can be used in the field when time, resources and data may not be readily available.
\end{abstract}

Keywords: military, base camps, siting, MCDA, risk, decision analysis

\section{Introduction}

Base camps are vital components of overseas military missions and must provide four key functions: (1) force protection; (2) critical infrastructure (e.g. housing, maintenance areas, dining facilities, aid stations, chapels, postal service centre, electric power, water treatment, fuel storage, road networks and athletic fields); (3) training support; and (4) maintenance support (Ezell et al. 2001).

\footnotetext{
*Corresponding author: Jeffrey C. Cegan, E-mail: jeffrey.c.cegan@usace.army.mil Maureen S. Golan, U.S. Army Corps of Engineers
}

Providing these functions in a dynamic environment requires complex planning, development and evaluation of site suitability by a team of subject-matter experts (e.g. a Location Selection Team or Forward Engineering Support Team (FEST)). Although flexible, these teams are usually led by one officer-in-charge, and are comprised of one non-commissioned officer and six highly skilled U.S. Army Corps of Engineers (USACE) civilian technical experts, who work together to determine base camp locations within an area of interest (AoI) (USACE 2009). Each alternative site's suitability is evaluated based on a variety of factors that can reduce risk and maximise mission effectiveness, and can be used in conjunction with Geographical Information Systems (GIS) data, software and/or capabilities. It is important to include a holistic evaluation of all relevant factors when assessing relative site suitability to address the U.S. Department of Defense (DOD) needs with the resources available. A formal decision-support tool could provide a useful framework for systematically comparing alternatives and ensuring inclusion of criteria that may otherwise be unintentionally overlooked or undervalued during the base camp selection process. This provides decision support for both planning and in-field purposes, as well as a platform for incorporating new information and lessons learned.

Geographic locations for base camp construction are prioritised as described by existing military doctrine (Ezell et al. 2001; Lindberg and Vargesko 2007; Lockridge 2017). The DOD has established guidelines for standardised base camp construction, operation, maintenance and security through such references as the 'RedBook,' 'SandBook' and Assistive Technology Planner (Lindberg and Vargesko 2007). While these construction guidelines discuss the broad intent of the doctrine, they leave many details to be interpreted without establishing criteria known to minimise mission risks beyond initial construction (Ezell et al. 2001; Parry and Kwarta 2001; Cegan et al. 2017a). This means that battlespace commanders responsible for determining site selection must interpret their site-specific research without specific decision guidance from military doctrine and without an established set of base camp 
suitability criteria. These limitations could potentially decrease the base-camp resiliency, introducing vulnerability for soldiers and ultimately compromising mission success rates (Parry and Kwarta 2001; Lockridge 2017).

There are several historical examples of base camp failures that highlight the need for a holistic and structured decision framework. For these sites, a formal framework could have influenced the base camp's initial location and allowed soldiers and commanding officers to have a greater awareness of the risk (or benefits) posed by the camp's location. Flawed siting locations over the past 15 years have resulted in base camp evacuations due to the detection of chemical, biohazard, nuclear and radiological hazards such as nerve and mustard gas and heavy metal contaminants (Williams 2002). They have also resulted in temporary closures due to unforeseen rain patterns and landslides and other large-scale environmental risks (Fisher 2012). On more than one occurrence, civilian engagement, threat levels, cultural norms, environment, enemy vantage points and topography constraints culminated in base camp closures, increased combat and international outrage (Ellinger et al. 2015; CNN 2009). While these closures and delays exemplify a base camp's effect on soldier safety, site suitability also impacts military spending during logistics operations such as supply and resupply (Marlott 2003). A tool would help reduce common risks: unnecessary vulnerability to dissatisfied locals, environmental risks like water supply contamination or slope destabilization, over-reliance on single supply routes that could lead to isolation and so on.

In order to assess base camp life cycle risks and maximise mission effectiveness and soldier safety, site suitability criteria must be compared across possible location alternatives. Multicriteria decision analysis (MCDA) provides an efficient methodology to assist siting teams wishing to strategically optimise their base camp location, weighting information in a holistic, balanced, quantitative and geographic approach. MCDA is a branch of operations research and management science that aids alternative selection in complex decision problems by providing a structured framework of criteria, value functions and weights to systematically aggregate individual details in a composite comparison of relative suitability. MCDA frameworks are powerful because they establish a common understanding among stakeholders and guide the process of incorporating subjective decision-maker tradeoffs into a transparent and defensible decision model (Keeney and Raiffa 1976; Linkov and Moberg 2011). Complex decision environments often require consideration of multivariate, conflicting spatial criteria to prioritise a set of alternatives (Malczewski 2006). MCDA tools can be introduced to help solve complex problems in a way that is practical and technically reliable and that can incorporate research, focus groups and surveys for criteria valuation along with spatial mapping or GIS-based considerations to include expanded neighbouring environments in the analysis as well (Huang et al. 2011). Although the military has developed some tools for supporting site selection (e.g. Geoblast, which considers a select set of mission parameters, and the ArmyBaseCamp/JFOB.net knowledge management system, which acts as a repository for documents and best practices), these are discrete tools lacking the ability to integrate cultural data, geographical data and engineering data into one decision-analysis framework (Ezell et al. 2001; Trainor et al. 2008).

Screening a large geographic area to find the most suitable location for a base camp requires consideration of various tradeoffs. MCDA can assist by explicitly capturing various insights and expertise of personnel involved in site selection in order to facilitate discussion and provide a transparent and cohesive process. By incorporating a GIS-based MCDA framework when locating military base camps, commanders will have accessible interfaces to help evaluate vulnerabilities, characterise and integrate multidimensional impacts and improve decision-making to mitigate spatially distributed risks.

Past applications of MCDA frameworks include land use development, transportation studies, site suitability for infrastructure (Hill et al. 2005; Hamilton et al. 2016; Yatsalo et al. 2010), nanotechnology management (Linkov et al. 2013; Bates et al. 2015; Bates et al. 2016), environmental risk management (Yatsalo et al. 2011), and humanitarian assistance and relief (Curran et al. 2014) with growing acceptance and application over time (Cegan et al. 2017b; Kurth et al. 2017). Given the success of these applications in informing site suitability decisions based on divergent criteria, we seek to apply similar MCDA methods with a new set of decision criteria related to increasing soldier safety and mission effectiveness through military base camp siting. To do this, we integrate expert elicitation and military doctrine regarding base camp life-cycles into a set of 10 criteria that can be used across a generic mission type to access and select alternative sites. We propose default weighting for these criteria from surveys with additional military commanders. However, this method must be tailored through scenario-specific weights and value functions. Inclusion of specific GIS tools, as appropriate based on uncertainty present in the area, can also be applied (Malczewski 2006). Finally, we apply these weights in an illustrative example and discuss the future work that would need to be done in order for the military 
to adopt this type of framework. This research contributes to the ongoing development of a new tool that will aid military teams in efficiently siting base camps and also allow for in-field decision support through the establishment of criteria and weights that are comprehensive, well-defined and easy to reference in situations calling for quick, unbiased and transparent decision-making.

\section{Methods}

\subsection{Criteria development}

During the criteria development process, the authors consulted with 14 current and former army officers (including 1 Colonel, 1 Lieutenant Colonel and 12 Captains) with experience in base camp siting and operations to discuss factors important for identifying promising sites for future base camps (Cegan et al. 2017a). While these conversations were naturally influenced by the US Army's more recent experience in the Middle East and the Balkans than past conflicts in South-East Asia, Europe, North Africa, or elsewhere, the interviews were steered to cover a variety of terrain, climatic and engagement conditions broadly relevant for expected future operations. These elicitations parallel the deep army history of After Action Reviews (AARs) by documenting lessons learned to identify areas of concern and develop criteria to focus on for improving site suitability assessment.

In addition to the officer interviews, relevant army literature on base camp siting, including descriptions of current doctrine and suggestions for future improvement, was reviewed to develop our list of key criteria. While often not as specific or prospective as the firsthand descriptions from the interviewees, over a dozen publically available military documents provided useful context and background knowledge related to base-camp siting. A list of these documents is included in Appendix A.

The officer interviews and army literature reviews resulted in identification of an initial list of potential factors relevant for base camp siting. However, benefits of a limited yet thorough development of criteria have been shown to improve both the transparency of the results and the consistency of weighting (Weber et al. 1988; Marttunen et al. 2017), and combined with the need for the capability for quick (in-field) decision-making, a large list of criteria is not ideal. Therefore, this initial list was then pared down to criteria judged to have been emphasised most consistently across the sources consulted, resulting in a total of 10 criteria. For these final criteria, summary definitions were developed that are clear and succinct, meeting the exhaustive, consistent, non-redundant, comprehensible and measurable requirements (Adiat et al. 2012) for use in MCDA analysis. Importantly, many of these criteria consider the holistic nature of the environment, drawing not only on site-specific (e.g. bounded) but also larger and broader environment factors, such as surrounding land use and access to the site, which incorporate the vital consideration that a basecamp is not independent of its larger setting and neighbours.

\subsection{Elicitation of default weights}

After the criteria were finalised, in-person surveys were conducted to develop default weights, which are used in an illustrative example in Section 3.3, which may provide a starting point for further scenario customisation in the decision-support tool, and can likewise be incorporated with larger spatial analysis programmes given available data and time through GIS software for further understanding of more specific neighbouring or direct threat. Surveys were conducted with 14 different officers attending the 85th Military Operations Research Symposium at West Point, NY on June 19-22, 2017. Due to the limited time available for in-person discussion and elicitation and the illustrative nature of the default weights, a simple and readily understandable approach of direct ranking and weighting was selected over alternate weight-elicitation techniques like swing weight elicitation (Winterfeldt and Edwards 1986). The officers were first asked to rank the criteria in importance from 1 to 10 and then use a four-star rating system for identifying relative criteria importance. The ranking exercise helped participants organise their broad thoughts before giving each criteria a specific rating of importance. Four stars were used for the rating system because research on surveys for valuation show that choice consistency is maximised when approximately four alternatives are given (Cook et al. 2007). The completed surveys were used to calculate the default weights for the MCDA model by averaging the star ratings across survey respondents normalised by the total number of stars indicated to derive percent weight.

\subsection{MCDA scoring algorithm}

The MCDA framework for base camp site suitability follows the method of Dodgson et al. (2000) and applies the following equation to the developed criteria and 
weights, where $S_{j}$ is the total MCDA score of alternative site $j, W_{i}$ is the weight calculated based on the surveys for criterion $i$ (or specified by the user) and $V_{i j}$ is the value of that alternative site location for that specific criterion, all of which fall on relative $0-1$ scales where higher values indicate greater importance or suitability. $V_{i j}$, may be the result of applying a normalising function $\left(V_{i j}=v_{i}\left(s_{i j}\right)\right)$ to alternative scores in their natural units $\left(s_{i j}\right)$, mapping raw scores to the $0-1$ relative suitability scale:

$$
S_{j}=\sum_{i=1}^{n} V_{i, j} \cdot W_{i}
$$

Sensitivity analysis was conducted to further examine the impact of criteria weighting on final alternative scores. The sensitivity analysis compares the default weights to equal weighting, rank-reciprocal weighting with the officer-supplied tradeoffs, and an 'opposite weight' scenario where the officers' rank order of criteria importance is entirely reversed prior to calculating rank-reciprocal weights (i.e. the most important criterion becomes the least important, the second most important criterion becomes the second least important etc.). This extreme scenario helps to show how much of the total score depends on the details of the officer's subjective weighting versus overwhelming differences in the site data. The results of this sensitivity analysis are shown in Appendix B.

Rank-reciprocal weights are calculated by normalising the reciprocals of each criterion's rank order of weight importance (recall that the officers were asked both to rank the criteria in terms of their importance for site assessment and then to directly provide numerical weights using a scoring system). The rank-reciprocal weight, $W_{j}$, for attribute $j$ is based on the specified rank, $r_{j}$, of the $j^{\text {th }}$ criterion and the number of criteria, $n$ (Stillwell et al. 1981):

$$
w_{j}=\frac{1 / r_{j}}{\sum_{k=1}^{n} 1 / r_{k}} .
$$

\section{Results}

\subsection{Developed criteria and their definitions}

The most important criteria for site selection are drawn from the expert interviews and review of relevant army literature. These are divided between criteria related to social and demographic data, special analysis of military communications capabilities available between that site and other existing facilities, civil infrastructure and terrain and environmental data (Table 1). Each of these types of information will be supported by different spatial data sources.

These criteria are relevant for screening-level assessments of potential alternatives within an AoI, leaving many case-specific considerations to be further evaluated by the siting team outside of the MCDA framework before final site selection. The AoI includes both the potential site and the potential immediate surroundings due to its intentional scope. Smaller terrain features such as ditches, hilltops and gullies will also need to be considered for specific facility placement within any chosen site. Note that a score of zero indicates poor performance in that area rather than a 'no build zone' (which is specially designated by the military outside of this process); any fully unfeasible alternatives should be screened out before starting the MCDA analysis.

The criteria are defined as follows:

- Land cover: Ecological systems influence barriers from direct and indirect weapon fire, adversarial groups and air-to-ground concealment. The presence of different vegetation (i.e. desert, brush, forest, swamp etc.) helps to optimise the construction process and ultimate protection of the base as well as affecting Touch Down and Liftoff (TLOF) and Final Approach and Takeoff (FATO) areas. In all scenarios, it is recommended that commanders maximise the use of natural features to obscure visibility from various threat vantage points.

- Aquifer access: Access to water is crucial for health, safety and security and the means of access greatly influences the life-cycle cost of a base camp. Well viability is dependent on water table depth,

Tab. 1: Key criteria for base camp siting, categorised by data type

\begin{tabular}{ll}
\hline Criteria & Type of data \\
\hline $\begin{array}{l}\text { Population } \\
\text { Enemy/threat }\end{array}$ & Social/demographic \\
Interference/signal & $\begin{array}{l}\text { Capability analysis } \\
\text { Roads }\end{array}$ \\
Local utilities & \\
Slope & Terrain/environment \\
Soils & \\
Land cover & \\
Aquifer access & \\
Land use & \\
\hline
\end{tabular}


water quality and impact on the local population and agriculture. Building on an area with a very high water table should also be avoided (due to potential flooding).

- Slope: Slope affects landing zone selection, parking lots, roadways, constructability and storm water management. A commonly accepted range is $2-7 \%$ grade, with specifics varying with intended use.

- Soils: Soil type impacts construction of roadways, culverts, drainages, trenches, latrines, waste disposal/management sites and base camp perimeters, and the susceptibility of roadways to collapse. Some soil types may be prone to erosion, necessitate dust abatement actions or be incapable of being easily shovelled.

- Roads: Pre-existing road networks influence base camp security and support mechanisms (e.g. part of the facility's future supply route). Roads also impact the presence of buffer zones from the base camp to exterior vehicular traffic, control levels of vehicle access into the base camp and can lead to potentially dangerous one-road-in/one-road-out scenarios.

- Local utilities: Local utilities effect overall base camp construction, ongoing support, accessibility, life-cycle cost and environmental impact. Electric power, drinking water treatment and wastewater treatment are crucial utilities for base camp support and safety. Commanders are increasingly encouraged to rely on existing commercial infrastructure as a primary source of power, with generators and fuel supply as a secondary option; viability of distributed/renewable energy to increase economic benefits and reduce environmental impacts is also increasingly considered. Similarly, in optimal base camp scenarios, connection to local water supply sources is preferred.

- Interference/signal: Communication is essential for carrying out military objectives and signal officers note that existing communications, radio towers or buildings may severely interfere with field communications on the ground. Nearby electromagnetic devices that consume large amounts of electricity (e.g. large ventilator motor and elevator motor) may cause temporary aberrations in the helicopter magnetic compass or other onboard navigational equipment. Furthermore, at times it may be essential for base camps to have line-of-site communication within their extended network.

- Population: Local population proximity and size determine the availability of local workers, equipment and services that can be utilised for base camp construction, operation tasks and security operations. Furthermore, nearby population sizes may influence base camp functions, needs and efficacy in counterinsurgency (COIN) missions. Proximity to other base camps or host nation forces also allows for support in the case of an attack.

- Threat/enemy: Proximity to enemy populations influences enemy engagement and the command and control of decisive battlespace terrain. Threat levels and estimated severity of threats determine vulnerability reduction requirements and facility needs, thereby affecting such factors as the physical layout of facilities, facility groups and infrastructure. Additionally, the threat level during the expeditionary stage and initial construction of a base camp is affected by the existence and type of built environment present in hostile scenarios and by the type and quantity of indigenous construction materials readily available for the base construction crews to create protective barriers.

- Land use: The presence and distribution of rural, urban, industrial, religious, medical, educational, transportation and existing land use impact the resources available for use, e.g. for new airfield construction. The overall level of development and layout of the existing man-made environment can also affect security concerns, since these facilities may obscure visibility from various vantage points.

\subsection{Criteria weights}

Fourteen officers across the army were surveyed to determine default criteria weights (Table 2). The results, ranging from $7.5 \%$ to $12.6 \%$, show no clear categorical trend related to the data types outlined in Table 1.

Tab. 2: Average ranking and importance order comparison and calculated weighting

\begin{tabular}{lc}
\hline Criteria & Calculated weight (\%) \\
\hline Roads & 12.6 \\
Threat/enemy & 12.0 \\
Slope & 11.7 \\
Soils & 11.5 \\
Population & 10.1 \\
Local utilities & 9.8 \\
Land cover & 8.9 \\
Aquifer access & 8.1 \\
Interference/signal & 7.8 \\
Land use & 7.5 \\
\hline
\end{tabular}


Tab. 3: Alternative regions for suitable base camp sites based on criteria scores

\begin{tabular}{|c|c|c|c|c|c|c|c|c|c|c|}
\hline Alternatives & Roads & $\begin{array}{l}\text { Threat/ } \\
\text { enemy }\end{array}$ & Slope & Soil & $\begin{array}{c}\text { Local } \\
\text { utilities }\end{array}$ & Population & Land cover & $\begin{array}{l}\text { Aquifer } \\
\text { access }\end{array}$ & $\begin{array}{c}\text { Interference/ } \\
\text { signal }\end{array}$ & Land use \\
\hline Site 1 & 0.6 & 0.8 & 0.2 & 0.8 & 0.7 & 0.3 & 0.7 & 0.3 & 0.8 & 0.5 \\
\hline Site 2 & 0.9 & 0.2 & 0.0 & 0.3 & 0.5 & 0.2 & 0.3 & 0.9 & 0.4 & 0.3 \\
\hline Site 3 & 0.9 & 0.8 & 0.3 & 0.7 & 0.8 & 0.9 & 0.3 & 0.5 & 0.0 & 0.3 \\
\hline Site 4 & 0.7 & 0.3 & 0.1 & 0.9 & 0.3 & 0.8 & 0.6 & 0.4 & 0.3 & 0.8 \\
\hline Site 5 & 0.9 & 0.8 & 0.6 & 0.9 & 0.7 & 0.7 & 0.7 & 0.5 & 0.7 & 0.9 \\
\hline Site 6 & 0.4 & 0.1 & 0.5 & 0.1 & 0.4 & 0.2 & 0.8 & 0.0 & 0.3 & 0.2 \\
\hline Site 7 & 0.9 & 0.9 & 0.9 & 0.6 & 0.6 & 0.7 & 0.8 & 0.9 & 0.9 & 0.5 \\
\hline
\end{tabular}

\section{3 llustrative example}

To demonstrate the MCDA site selection framework, seven hypothetical site alternatives within an AoI are evaluated in an illustrative example. Here, normalised value scores $\left(V_{i j}\right)$ for each alternative for each criterion were randomly generated between 0 and 1 (Table 3), where a score of 1 represents the best value and 0 represents the worst value for an individual criterion.

Table 4 shows the sum product of the alternative scores per criterion (Table 3 ) and the criterion weights (Table 2). The resulting total MCDA score $\left(S_{j}\right)$ allows each of the seven alternative sites to be ranked based on its overall relative site suitability for a base camp. In this illustrative example, locating a base camp at Site 7 has the highest level of suitability and Site 6 has the lowest level of suitability within the AoI. Sites 7 and 5, ranked 1st and 2nd as alternatives, have similarly high scores, with a significant gap between the 2nd and 3rd alternative, indicating that either site 7 or 5 may be acceptable to the army.

In addition to total score, the MCDA results allow one to drill-down and see why each alternative received its corresponding total score (Figure 1). That Site 7 ranked first overall is not surprising since it also has the highest values for the top three weighted criteria: roads, threat/ enemy and slope. Site 2 scores as high as Site 7 in suitability with respect to roads, but poor performance in other areas still leads to a low total score. Several sites outperform Site 7 in suitability with respect to population, but fail to generate superior scores in enough other areas to rank first. Site 5 ranks second after Site 7, with a somewhat different score profile, and might be preferable overall for base camp construction depending on the more detailed analyses performed next by the site selection team. These top two sites would be the recommended for further consideration and in-depth analysis.

This breakdown is also significant in showing that in-field decisions that must be made quickly (perhaps
Tab. 4: Ranking of alternative scores

\begin{tabular}{ll}
\hline Alternatives & Score \\
\hline Site 7 & 0.78 \\
Site 5 & 0.75 \\
Site 3 & 0.58 \\
Site 1 & 0.57 \\
Site 4 & 0.52 \\
Site 2 & 0.40 \\
Site 6 & 0.30 \\
\hline
\end{tabular}

for temporary basecamp siting) can prioritise the more heavily weighted criteria in decision-making. Although in an ideal situation all criteria should be leveraged for a final score, given limited or uncertain information and time, the higher weighted criteria can be used in the field, especially given the greater likelihood of physical visibility (roads and slope) or knowledge (threat/enemy) that military personnel would have on hand.

To represent these findings in a manner that can be used by a potential user interface in a selection tool, we employed a colour-coding system (Figure 2). Red shaded regions represent site locations having the lowest level of suitability $(\leq 0.50)$, yellow shaded areas represent alternative regions that pose a medium suitability (0.50-0.75), and green shaded areas represent regions believed to be best suited $(\geq 0.75)$ for a base camp in the MCDA screening analysis. While the diagram of results for the illustrative example has each alternative with an equal area, alternatives will likely vary in size in real settings. This clear visualisation enables more precise in-field selection of base camps by giving clear geographically ranked results.

A sensitivity analysis compared the final rank order of alternative scores using the calculated weights with other potential interpretations using equal weights, rank-reciprocal weights and rank-inverse weights. The results (Tables B1 and B2 in Appendix B) show that the final rank order of alternative sites does not vary between equal weighting and rank-reciprocal 


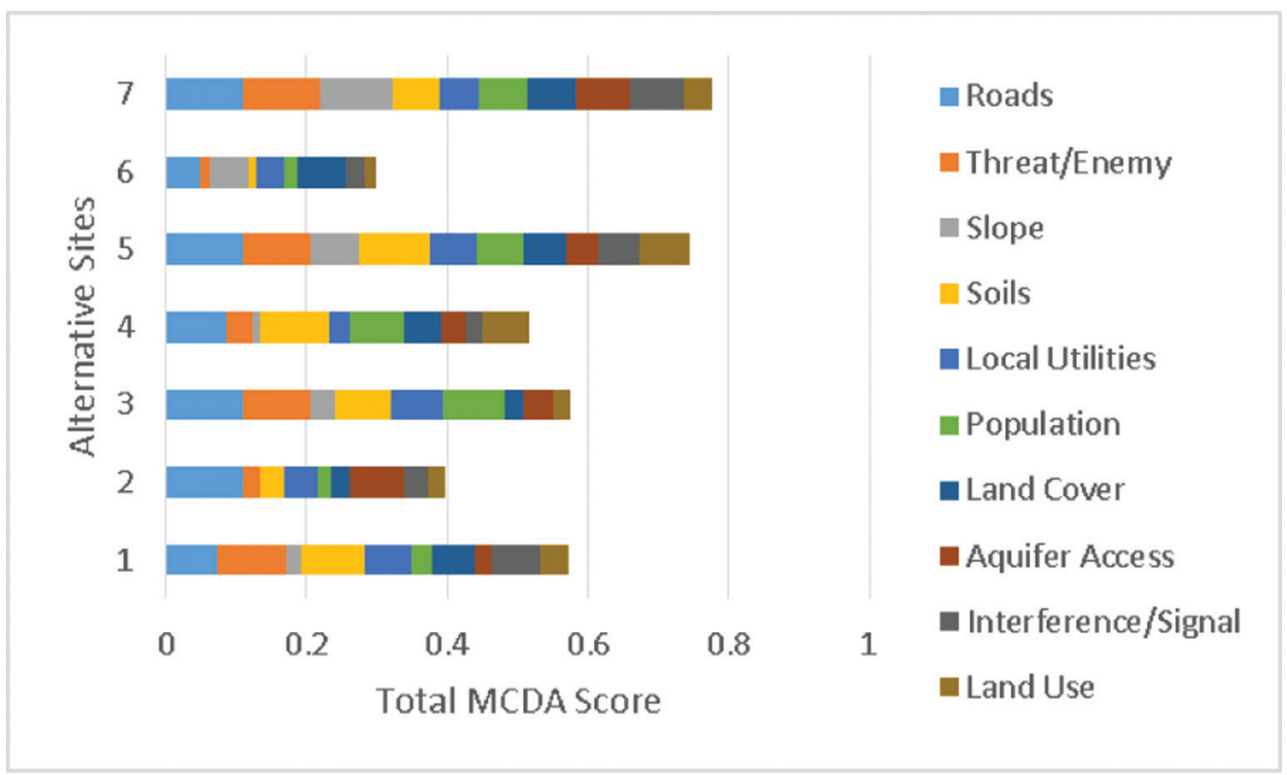

Fig. 1: MCDA factor distribution by alternative site. MCDA, multicriteria decision analysis.

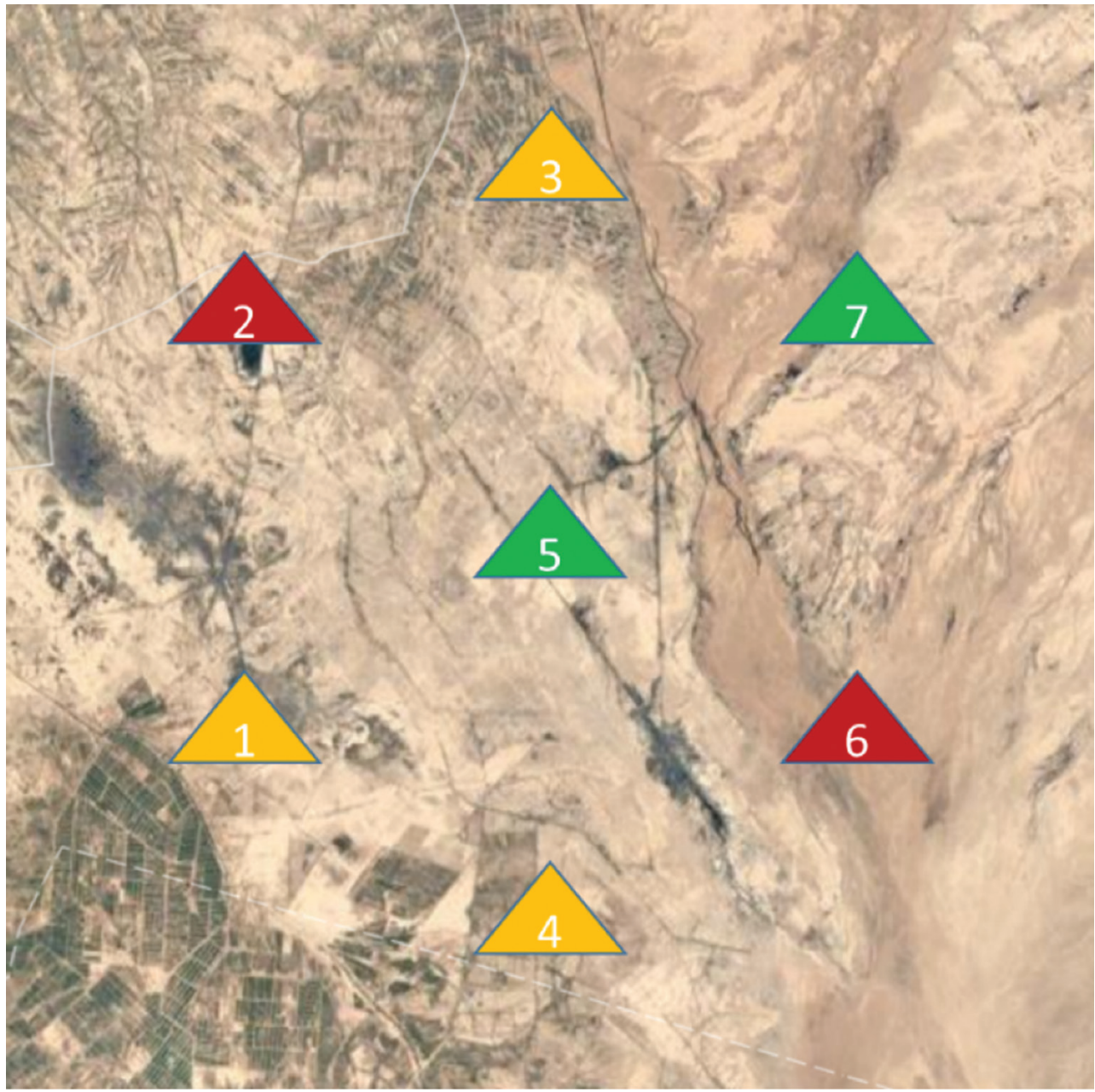

Fig. 2: Colour-coded ranking of alternative sites within an Aol. Aol, area of interest. 
weighting and varies only slightly between default weighting and equal weighting. In the opposite-weight scenario, the results are still largely similar, with two alternatives not changing final rank order, four changing rank order by one place, and one changing rank order by two places.

\section{Summary and Conclusion}

The results from expert elicitation show that, at default, the three most heavily weighted criteria are roads, threat/ enemy and slope, with weights of $12.6 \%, 12.0 \%$ and $11.7 \%$ respectively. It makes sense that the roads criterion, which relates to vital factors such as safety, logistics/life cycle and constructability, is heavily weighted. As soldier safety and mission effectiveness are of upmost importance and hinge on threat/enemy, this criterion is also valued highly. Slope is at the intersection of logistics/life cycle and safety, because it is a consideration for friendly air resupply and hostile ambush scenarios, among other factors. Decision-makers in the field can leverage prior knowledge of the prioritisation/ranking of the criteria to best manage resources and time as necessary or under uncertainty.

The least valued criteria, interference/signal and land use, are not as cross-cutting across base camp requirements such as constructability, logistics/life cycle and soldier safety. Although further elicitations must be conducted to fine-tune the weights for specific implementations, these results can serve as default guidelines for a base camp site suitability in a decision-support tool. A visual colour-coding ranked output within an AoI gives a valuable starting point for basecamp exploration, and such a portable tool could be used in the field to fine-tune the results as additional data becomes available.

The illustrative example in this paper explores site locations for a hypothetical base camp tasked with a broad mission. For base camps established for specific purposes (e.g. humanitarian assistance, COIN operations, enemy engagement etc.), tailored weights need to be applied that best fit the needs of the mission. Optionally, weight templates that provide a range of more specific default weights appropriate for a handful of common scenarios can anticipate these different needs and provide a non-unique but tailored starting point for case-specific use.

Due to the complexity and case-specific nature of multifaceted base camp objectives, defining the value functions used to derive criteria values $\left(V_{i j}\right)$ is an exercise left to the practitioner. Belton and Stewart (2002) provide good guidelines and further details for MCDA practical application. Nevertheless, our illustrative example shows that MCDA has the potential to streamline the site evaluation and process and increase mission success by identifying those potential sites that are expected to have the best risk-benefit tradeoffs and by ensuring that a broad range of relevant criteria are consistently included in these types of analyses. A colour-coded map and user interface in the tool that is expected to be developed in the future will enable efficient decision support, leading to lower economic burdens across the base camp's life cycle, greater suitability and increased mission success.

Existing military doctrine and literature show that there are many factors to consider in base camp site selection, and that taking a comprehensive approach to quantitatively organising and streamlining criteria valuation is necessary. MCDA can streamline the base-camp selection process. Through careful development of the 10 top criteria and expert elicitation across a range of military personnel with base camp experience, criteria and default weights were generated that can broadly aid the process. With case-specific value functions, these will provide an explicit framework for determining site suitability of military base camps. Once vetted by the military approval process, these results are intended to be incorporated into the Engineer Site Identification for the Tactical Environment (ENSITE) tool for determining suitability of potential base camp sites, currently under development by the USACE Environmental Research and Development Center (ERDC).

This paper highlights current work on an MCDA military base camp site suitability process and tool. Further work remains to be done on developing the value functions and perhaps developing more specific weighing templates for some common mission and environmental scenarios. Value functions are important because they normalise raw data in a way that allows for otherwise incomparable information to be transparently included in a comprehensive evaluation. Value function identification is necessary for any MCDA framework to be robust (Malczewski and Rinner 2015).

Due to economic and time constraints, many uncertainties will remain in most pragmatic MCDA evaluations. One approach for prioritising further information gathering to reduce uncertainty is Value of Information (VoI) analysis. Although all the criteria are vital when evaluating the suitability of a base camp, some criteria may present a larger need for measurability over others (e.g. interference/signal may not be mapped by the military data sets across a geographic AoI). In the context 
of minimising risk of mission failure, some uncertainties naturally matter more than others. Similarly, investments in information gathering to resolve uncertainties (e.g. investments to improve road or aquifer datasets) can differ widely in costs. VoI analysis would combine these factors to prioritise resolving the most valuable uncertainties, and only those that are likely to lead to substantially different outcomes in terms of recommended base camp alternatives (Keisler et al. 2014). Future work could also incorporate VoI analysis into base camp site-suitability assessments.

\section{References}

Adiat, K. A. N., Nawawi, M. N. M., \& Abdullah, K. (2012). Assessing the accuracy of GIS-based elementary multi criteria decision analysis as a spatial prediction tool - A case of predicting potential zones of sustainable groundwater resources. Journal of Hydrology, 440-441, pp. 75-89.

Bates, M. E., Grieger, K., Trump, B., Keisler, J., Plourde, K., \& Linkov, I. (2016). Emerging technologies for environmental remediation: Integrating data and judgment. Environmental Science \& Technology, 50.1, pp. 349-358.

Bates, M. E., Larkin, S., Keisler, J., \& Linkov, I. (2015). How decision analysis can further nanoinformatics. Beilstein Journal of Nanotechnology, 6, p. 1594.

Belton, V., \& Stewart, T. (2002). Multiple Criteria Decision Analysis: An Integrated Approach. Springer, Boston.

Cegan, J., Calfas, G., \& Bates Matthew, E. (2017a). ERdc Risk and Decision Science Team Support for: Contingency Base Site Identification for the Tactical Environment (CB-SITE) Project. Technical Report, U.S. Army Corps of Engineers.

Cegan, J., Filion, A., Keisler, J., \& Linkov, I. (2017b). Trends and applications of multi-criteria decision analysis in environmental sciences: Literature review. Environment Systems and Decisions, 37(2), pp. 123-133

CNN. (July 31, 2009). U.S. Troops Accused Of Damaging Babylon's Ancient Wonder. Available at http://edition.cnn.com/2009/ WORLD/meast/07/31/iraq.babylon.damage/ [29 June, 2017].

Cook, H. E., \& Wissmann, L. A. (2007). Value Driven Product Planning and Systems Engineering. Chapter 2: Assessing Value Using Surveys. Springer, London.

Curran, R. W., Bates, M. E., \& Bell, H. (2014). Multi-criteria decision analysis approach to site suitability of US department of defense humanitarian assistance projects. Procedia Engineering, 78, pp. 59-63.

Dodgson, J., Spackman, M., Pearman, A., \& Phillips, L. (2000). Multi-Criteria Analysis: A Manual, report to the Department of Environment, Transport and the Regions, Eland House, Bressenden Place, Long SW1E 5DU.

Ellinger, A. H., Powell, D., Stokes, J., Showalter, W., \& Tucker, R. (2015). Use of indigenous materials: For construction in the modern base camp. Engineer, May 1, 2015, pp. 42-47.

Ezell, M. B. C., Davis, L. C. M. J., \& McGinnis, C. M. L. (2001). Base camp design: Site selection and facility layout. Operations Research, p. 40.
Fisher, F. (2012). Area I Staged For Possible Repeat of Monsoon Flooding. U.S. Army. Available at https://www.army.mil/ article/81627/Area_I_staged_for_possible_repeat_of_ monsoon_flooding[accessed 29 June, 2012].

Hamilton, M., Nezda, J., Doody, P., Bates, M., Bauer, N., Voyadigs, D., et al. (2016) Web-based geospatial multiple criteria decision analysis using open software and standards. International Journal of Geographical Information Science, 30(8), 1667-1686.

Hill, M. J., Braaten, R., Veitch, S., Lees, B., \& Sharma, S. (2005) Multi-criteria decision analysis in spatial decision support: The ASSESS analytic hierarchy process and the role of quantitative methods and spatially explicit analysis. Environmental Modelling \& Software, 20, pp. 955-976.

Huang, I. B., Keisler, J., \& Linkov, I. (2011). Multi-criteria decision analysis in environmental sciences: Ten years of applications and trends. Science of the Total Environment, 409, pp. 3578-3594.

Keeney, R. L., \& Raiffa, H. (1976). Decisions with Multiple Objectives: Preferences And Value Tradeoffs. Wiley, New York.

Keisler, J., Collier Z., Chu, E., Sinatra, N., \& Linkov, I. (2014). Value of information analysis: State-of-the-application. Environment Systems and Decisions, 34, pp. 3-23.

Kurth, M., Keisler, J., \& Linkov, I. (2017). Trends and applications of multi-criteria decision analysis: Use in government agencies. Environment Systems and Decisions, 37(2), pp. 134-143.

Lindberg, T., \& Vargesko, A. (2007). U.S. army battle command knowledge system: Knowledge management for the base camp community of practice. Engineer, October-December, p. 15-16.

Linkov, I., \& Moberg, E. A. (2011). Multi-Criteria Decision Analysis: Environmental Applications And Case Studies. CRC Press, Boca Raton, FL.

Linkov, I., Bates, M. E., Trump, B., \& Seager, T. (2013).. For nanotechnology decisions, use decision analysis. Nano Today, 8(1), pp. 5-10.

Lockridge, J. (2017). Are you ready for the net zero logistics base camp? Engineer, 47(1), pp. 12-15.

Malczewski, J., \& Rinner, C. (2015). Multicriteria Decision Analysis in Geographic Information Science. Springer, Berlin.

Malczewski, J., (2006). GIS-based multi criteria decision analysis: A survey of the literature. International Journal of Geographical Information Science, 20(7), pp. 703-726.

Marlott, R. M. (2003). Integrated life cycle base camp sustainment. Engineer, October-December, p. 38-41.

Marttunen, M., Lienart, J., \& Belton, V. (2017). Structuring problems for multi-criteria decision analysis in practice: A literature review of method combinations. European Journal of Operational Research, 263(2017), pp. 1-17.

Parry, B. R., \& Kwarta, C. J. (2001). USMa basecamp decision support system. Systems Engineering Capstone Conference: University of Virginia. United States Military Academy, West Point, NY.

Stillwell, W. G., David, A. S., \& Edwards, W. (1981). A Comparison of weight approximation techniques in multiattribute utility decision making. Organizational Behavior and Human Performance, 28(1), pp. 62-77.

Trainor, T. E., Brazil, D. M., \& Lindberg, T. (2008). Building knowledge from organizational experience: Approaches and lessons learned from US army base camp workshops. Engineering Management Journal, 20(2), pp. 37-45.

U.S. Army Corps of Engineers. (2009). Base camp development in the theater of operations. Engineer Pamphlet No. 1105-3-1. 
Available at http://www.publications.usace.army.mil/ Portals/76/Publications/EngineerPamphlets/EP_1105-3-1.pdf

Weber, M., Eisenführ, F., \& von Winterfeldt, D. (1988). The effects of splitting attributes on weights in multiattribute utility measurement. Management Science, 34(4), 431-445.

Williams, C. J. (2002). Traces of Nerve Gas Found at Uzbek Base Used by U.S. Los Angeles Times. Available at www.latimes.com. [accessed 26 June, 2017].

Winterfeldt, D., \& Edwards, W. (1986). Decision Analysis and Behavioral Research. Cambridge University Press, Cambridge.
Yatsalo, B., Didenko, V., Tkachuk, A., Gritsuk, S., Mirzeabasov, O., Slipenkaya, V., et al. (2010). Multi-criteria spatial decision support system DECERNS: Application to land use planning. International Journal of Information Systems and Social Change, 1, pp. 11-30.

Yatsalo, B., Sullivan, T., Didenko, V., \& Linkov, I. (2011). Environmental risk management for radiological accidents: integrating risk assessment and decision analysis for remediation at different spatial scales. Integrated Environmental Assessment and Management, 7, pp. 393-395. 


\section{Appendix A}

USACE Overseas Contingency Operations Playbook, No 16-01. Public Access at: http://usacac.army.mil/organizations/mccoe/call/ publication/16-01

Base Camp Facilities Standards for Contingency Operations (the Red Book). Public Access at: http://www.eur.army.mil/pdf/ Red_Book.pdf

U.S. Army Training and Doctrine Command (TRADOC) Pamphlet 525-7-7 (2009) Army Base Camps in Full Spectrum Operation for the Future Modular Force 2015-2014. Public Access at: http://adminpubs.tradoc.army.mil/pamphlets/ TP525-7-7.pdf

Gingras (2013) The Challenge of Modern Contingency Base Management during Sustained Land Operations. Public Access at: http://www.dtic.mil/get-tr-doc/pdf?AD=ADA592892

Central Command Regulation [CCR] 415-5 (The Sand Book). Public Access at: https://www.scribd.com/document/43668937/ The-Sand-Book

ATP 3-37.10/MCRP 3-17.7N - Base Camps. Public Access at: http:// www.marines.mil/Portals/59/MCRP\%203-17.7N\%20z.pdf

Corson and Jasperro (2007) An All-Hazards Approach to U.S. Military Base Camp Site Selection. Public Access at: https:// gammathetaupsilon.org/the-geographical-bulletin/2000s/ volume48-2/article2.pdf

Krooks et al. (2012) Contingency Bases and the Problem of Sociocultural Context. Public Access at: http://www.dtic.mil/ $\mathrm{dtic} / \mathrm{tr} /$ fulltext/u2/a568613.pdf

ADP 5-0 (2012). The Operations Process. Public Access at: https:// apps.dtic.mil/sti/pdfs/ADA568613.pdf

Challenging the Application of PMESII-PT in a Complex Environment (2010). Public Access at: https://pdfs.semanticscholar. org/32aa/722aa90378caeaf589b425693f0d5e769c6e.pdf

Ezell et al. (2001). Base Camp Design: Site Selection and Facility Layout. Public Access at: https://www.researchgate.net/ publication/235163800_Base_Camp_Design_Site_Selection_ and_Facility_Layout?ev=auth_pub

ATP 5-19 (2014). Risk Management. Public Access at: http:// www.benning.army.mil/RangeOps/content/blank_forms/ ATP_5-19RiskManagement_Apr14.pdf

U.S. Army Corps of Engineers. Base Camp Development in the Theater of Operations. Engineer Pamphlet No. 1105-3-1. 19 January 2009. Public Access at: https://www.scribd.com/ document/357547004/EP-1105-3-1-pdf

\section{Appendix B}

The various weight sets used for sensitivity analysis are presented in Table B1. The equal weight case treats all criteria as equally important and the rank-reciprocal case calculates weights based on applying a consistent formula to the interviewee-supplied ranks instead of using their direct scoring of criteria weight. The 'opposite weight' scenario shows an extreme, hypothetical case where criteria rank order is reversed prior to calculating rank-reciprocal weights (i.e. the most important criterion becomes the least important, the second most important criterion becomes the second least important etc.). While not a realistic reflection of the priorities of the Army interviewees, it does provide valuable insights for the sensitivity analysis in exploring the stability of results and the extent to which the resulting rank order of alternatives is governed by intricacies of criteria weighting versus differences in alternative performance. This provides a type of stress-test for the illustrative example to changes in weighting.

The rank order of alternative sites found by applying different weighting schemes to the existing site performance data is presented in Table B2. Notice that these weighting schemes have not generally lead to a significantly different final rankings of alternatives. The equal and rank-reciprocal weights are both only changing the rank order of sites 1 and 3 between 3rd and 4th

Tab. B1: Four sets of criteria weights used for sensitivity analysis

\begin{tabular}{lcccc}
\hline Criteria & Calculated weight (\%) & Equal weight (\%) & Rank-reciprocal weight (\%) & Opposite-weight scenario (\%) \\
\hline Roads & 12.6 & 10.0 & 34.1 & 3.4 \\
Threat/Enemy & 12.0 & 10.0 & 17.1 & 3.8 \\
Slope & 11.7 & 10.0 & 11.4 & 4.3 \\
Soils & 11.5 & 10.0 & 8.5 & 4.9 \\
Population & 10.1 & 10.0 & 6.8 & 5.7 \\
Local utilities & 9.8 & 10.0 & 5.7 & 6.8 \\
Land cover & 8.9 & 10.0 & 4.9 & 8.5 \\
Aquifer access & 8.1 & 10.0 & 4.3 & 11.4 \\
Interference/Signal & 7.8 & 10.0 & 3.8 & 17.1 \\
Land use & 7.5 & 10.0 & 3.4 & 34.1 \\
\hline
\end{tabular}


Tab. B2: Rank ordering of alternative sites across weighting schemes

\begin{tabular}{lcccc}
\hline Alternatives & Calculated weight & Equal weight & Rank reciprocal weight & Opposite-weight scenario \\
\hline Site 1 & 3 & 4 & 4 & 4 \\
Site 2 & 6 & 6 & 6 & 6 \\
Site 3 & 4 & 3 & 3 & 5 \\
Site 4 & 5 & 5 & 5 & 3 \\
Site 5 & 2 & 2 & 2 & 1 \\
Site 6 & 7 & 7 & 7 & 7 \\
Site 7 & 1 & 1 & 1 & 2 \\
\hline
\end{tabular}

place compared to the calculated weights. The stress-test opposite-weight scenario resulted is a greater shuffling of site rankings, but still only shifted 4 sites by 1 place and 1 site by 2 places, with 2 sites retaining their same rank order as under the calculated weights.

This analysis increases confidence in the results in the illustrative example because ranking of sites remain highly consistent across different weighting schemes. Though each case is unique, other studies and analytic efforts have generally confirmed that high value can be achieved in MCDA through use of inexact weights, sub-optimal weighting strategies and weights from different stakeholders (Keisler 2009; Edwards and von Winterfeldt 1986; Yatsalo et al. 2007). This suggests that analytic efforts to support base camp suitability analysis may better focus on incorporating additional criteria or improving value functions than on improving weight estimates in the MCDA.

\section{References for Appendix B}

Keisler, J. (2009). The value of assessing weights in multi-criteria portfolio decision analysis. Journal of Multi-Criteria Decision Analysis, 15, pp. 111-123.

Von Winterfeldt, D., \& Edwards, W. (1993). Decision Analysis And Behavioral Research. Cambridge University Press, Cambridge, UK.

Yatsalo, B. I., Kiker, G. A., Kim, J., Bridges, T. S., Seager, T. P., Gardner, K., et al. (2007). Application of multicriteria decision analysis tools to two contaminated sediment case studies. Integrated Environmental Assessment and Management, 3(2), pp. 223-233. 